GRASAS Y ACEITES 65 (1)

January-March 2014, e006

ISSN-L: 0017-3495

doi: http://dx.doi.org/10.3989/gya.049813

\title{
Time course of muscle fatty acid composition of cultured meagre (Argyrosomus regius) during the first sixteen months of a cage culture
}

\author{
S. García Mesa ${ }^{a}$, M.D. Suárez, ${ }^{\mathrm{b},}$, M.A. Rincón Cerverac ${ }^{\mathrm{c}}$ J.L. Guil Guerreroc \\ G. González ${ }^{\mathrm{a}}$, S. Cárdenas ${ }^{\mathrm{d}}$ and M. García Gallego ${ }^{\mathrm{a}}$ \\ a Zoology Department, University of Granada, 18001 Granada (Spain) \\ bBiology and Geology Department, University of Almería, 04120 Almería (Spain) \\ ${ }^{\mathrm{C}}$ Food Technology Division, University of Almería, 04120 Almería (Spain) \\ ${ }^{d}$ IFAPA Centro El Toruño, 11500 El Puerto de Santa María, Cádiz (Spain) \\ Corresponding author: dsuarez@ual.es
}

Submitted: 30 April 2013; Accepted: 23 September 2013; Published on line: 13/02/2014

SUMMARY: Juvenile meagre were sampled at intervals during their first 500 days in a cage-based fish farm. Fish muscle showed a relatively low fat content (0.65-2.0\%) when compared with other species of farmed fish, corroborating the consideration of meagre as a lean fish. At the beginning of the assay, saturated and monounsaturated fatty acids were in a similar proportion (approximately 30\%), while polyunsaturated were close to $39 \%$ of total FAs, the $n-3: n-6$ ratio being of 3.8. Throughout the experiment a notable reduction in the sum of PUFA n-3 and an increase of linoleic (18:2n-6) and oleic acid (18:1n-9) was found. These changes led to a fall of $n-3: n-6$ ratio to values close to or lower than 1.0. Most probably, these changes reflect variations in the feeding regime applied during farming. In any case, fish offered good indices of lipid quality for human consumption.

KEYWORDS: Aquaculture; Argyrosomus regius; Fatty acids profile; Muscle; $n$-3:n-6 ratio

RESUMEN: Evolución del contenido en lípidos y ácidos grasos del músculo de la corvina (Argyrosomus regius) durante los primeros dieciséis meses de cultivo en jaulas flotantes. Se han muestreado corvinas juveniles durante los 500 primeros días de cultivo en jaulas flotantes. El contenido en grasa muscular fue relativamente bajo $(0,65-2 \%)$ en relación con otras especies de peces cultivados, lo que corrobora su consideración de pez magro. Al principio del ensayo, los ácidos grasos saturados y monoinsaturados mostraron una proporción del 30\%, mientras que los poliinsaturados de un 39\% del total de FAs, siendo la relación $n-3 / n-6$ de 3,8. A lo largo del periodo experimental hubo una reducción notable de PUFAs $n-3$ y un incremento de ácido linoleico (18:2n-6) y, en menor proporción, de ácido oleico (18:1n-9), lo que llevó a una disminución de la relación $n-3 / n-6$ hasta valores cercanos o menores de 1,0. Estos cambios reflejan variaciones en la composición del alimento durante el cultivo. En cualquier caso, la corvina ofrece buenos índices de calidad lipídica para la salud del consumidor.

PALABRAS CLAVE: Acuicultura; Argyrosomus regius; Músculo; Perfil de ácidos grasos; Relación n-3:n-6

Citation/Cómo citar este artículo: García Mesa S, Suárez MD, Rincón Cervera MA, Guil Guerrero JL, González G, Cárdenas S, García Gallego M. 2014. Time course of muscle fatty acid composition of cultured meagre (Argyrosomus regius) during the first sixteen months of a cage culture. Grasas Aceites 65 (1): e006. doi: http:// dx.doi.org/10.3989/gya.049813

Copyright: (C) 2014 CSIC. This is an open-access article distributed under the terms of the Creative Commons Attribution-Non Commercial (by-nc) Spain 3.0 Licence. 


\section{INTRODUCTION}

There is growing evidence that future fish needs for human consumption must be covered, in progressively higher proportion, by aquaculture and thus a sustainable development of this activity is needed.

One of the main quality indexes in farmed fish for human consumption is the lipid amount and fatty acid (FA) profile stored in the main edible fraction, the muscle. Some $n-3$ PUFAs have been regarded as essential for human health (WHO, 1977) for their role in preventing and treating a wide variety of disorders. Experts in human nutrition and health agree that fish included in the daily diet helps prevent certain diseases such as cardiovascular ones (Pirini et al., 2010). In this case, the beneficial effect seems to lie in the lipid component of fish and more specifically in the presence of certain inhibitors of platelet aggregation (Nasopoulou et al., 2007) and certain MUFAs and PUFAs, mainly those of the $n-3$ series.

Numerous studies have demonstrated the influence of the dietary FAs on their profile in fish tissues (Lie, 2001; Yildiz et al., 2008), but other factors could be also involved. The fish FA profile is certainly influenced by season (Leger et al., 1977, Shirai et al., 2002; Hassan et al., 2010) since the biochemical composition of marine organisms can undergo seasonal changes in this respect (Ackman, 1995). Also, the maturation degree significantly alters the FA profile of different fish tissues (Hussain et al., 2011).

Meagre (Argyrosomus regius) is receiving increasing attention for its reported good growth rate and easy adaptation to fish-farming practices. This species has been described as a particularly slender fish, even when it is cultured intensively, and even on a high-fat diet it provides high-quality commercial products. This fish has a high percentage of muscle, low fat, and healthy lipid content, so that it has a low index of atherogenicity and thrombogenicity (Poli et al., 2003). The organoleptic properties show that farmed meagre has no accumulation of perivisceral and muscle fat compared with other cultivated species. Also, it can be cool stored for long periods of time without sensory characteristics being affected (Hernández et al., 2009). Studies on the same species show that it provides low-fat meat even under intensive farming conditions (Piccolo et al., 2008). The low range of muscle lipids observed among dietary treatments implies that meagre, like other species, has a restricted ability for lipid deposition in muscle.

Recently, Chatzifotis et al., (2010) have observed that a $17 \%$ lipid diet was the most suitable for meagre in terms of growth, compared to $13 \%$ and $21 \%$. Proximate analysis indicated that the lipid content of whole body and muscle was affected by the diets, whereas of the liver remained unaffected.
The aim of the present work was to evaluate the influence of the growth stage on the time course of muscle fatty acid composition of meagre, over a 500-day period of their production cycle in a fish farm based in off-shore cages. This experimental period was designed to complete the evaluation of the possible effects of different culture factors on total muscle lipids and fatty acid content.

\section{MATERIAL AND METHODS}

\subsection{Animals, experimental conditions, and sampling}

Juvenile meagre (A. regius) 80 days old were enclosed in a cage-based fish farm (Ceutamar S.L., Algeciras Bay, southern Spain). Throughout the experimental period (504 days long after a prior 15-day adaptation period), fish were subjected to the usual production conditions operating in the fish-farm facilities. The recorded average temperature over a full year was $17.9 \pm 0.1^{\circ} \mathrm{C}$ (range 14.6$22.5^{\circ} \mathrm{C}$, Figure 1). Throughout the experimental period the salinity was around $37 \mathrm{ppt}$. The dissolved oxygen reached the minimum values during summer but levels never dropped below $7.2 \mathrm{ppm}$.

Fish were fed three times a day with a total daily ration of $2 \%$ body weight throughout the experiment. Two commercial diets specially designed for meagre intensive culture (Dibaq-Diproteg S.A.), were used. The first diet (Microbaq) was provided during the adaptation period and the first month of the experimental one, and then was gradually replaced by the second diet (Alphamar). According to the manufacturers, the diets were based on fish meal and oil, soya protein and oil, wheat meal and gluten, pea meal, vitamins, and minerals. Diets were analysed for crude protein, crude lipid, and ash according to AOAC methods (2000) and FA composition. The composition is listed in Table 1, reflecting that the Microbaq diet had higher protein/lower fat levels and a higher protein:energy ratio than did Alphamar although the total energy content was similar in both diets. On the other hand, the diets varied in their FA profile, in that the Microbaq diet contained higher levels of PUFA n-3 but was lower of linoleic (LA) and oleic (OA) acids than Alphamar, resulting in a clearly higher $n 3: n 6$ ratio than in the starter diet. These situations most presumably reflect different amounts of fish and vegetable oils in the two diets.

Fish were sampled every 1-2 months except for sampling \#9, which was delayed five months.

Each sample was based in 50-100 fish (the highest figure for the seven first samples, the lowest for later ones; according to the predefined practices at the fish farm) that were weighed and measured to follow the time course for growth; five of these fish, also taken at random, were independently analysed to determine the fillet composition. Samples were 


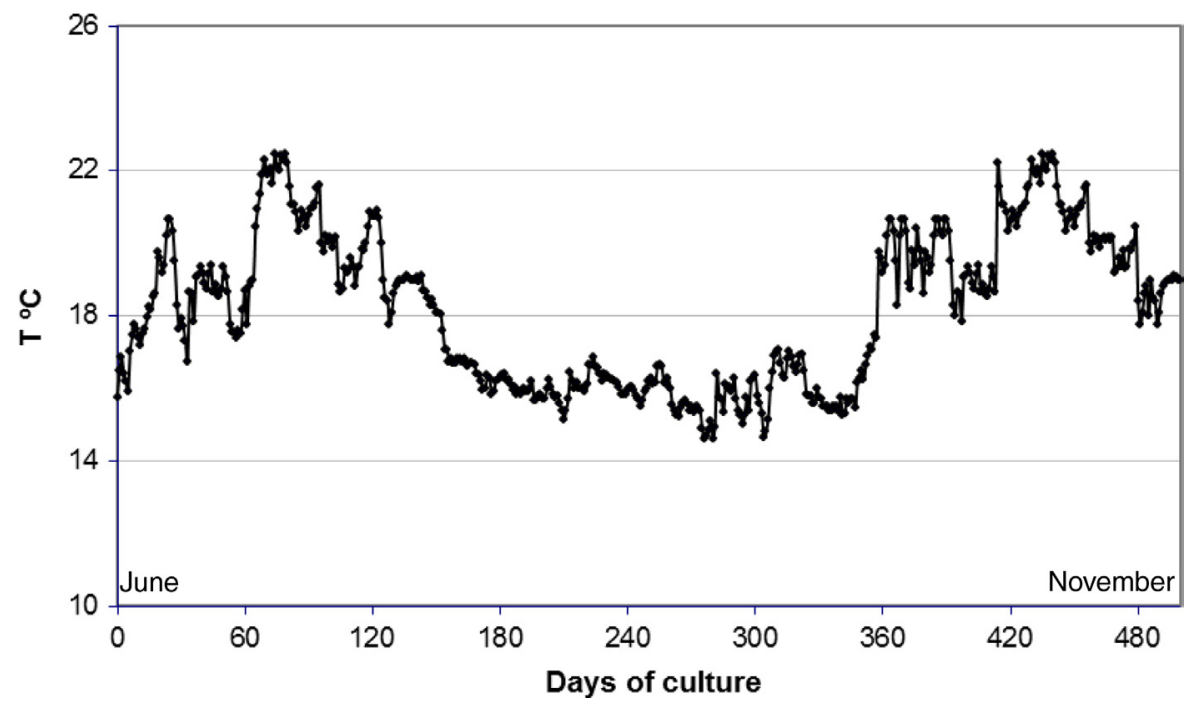

FIGURE 1. Time course of the water temperature.

taken after a 24-h food-deprivation period and the fish were rapidly killed following the Directive 2010/63/EU (overdose of metacaine, approved killing protocol).

\subsection{Fish analyses}

After skin removal, whole fillets of sampled fish were dissected. Muscles were ground, freeze-dried, and analysed for total lipids and fatty acid (FA) composition.

Total lipids were extracted gravimetrically after homogenizing twice in choloroform/methanol $(2: 1, \mathrm{v} / \mathrm{v})$ for $3 \mathrm{~min}$ in a Waring blender (Folch et al., 1957).

For FA extraction and transesterification, samples of diet and muscle $(20 \mathrm{mg})$ were mixed with $20 \mathrm{~mL}$ of a solution of methanol:acetyl chloride $(20: 1, \mathrm{v} / \mathrm{v})$ and $20 \mathrm{~mL}$ hexane, as previously described (Rodríguez-Ruiz et al., 1998). The mixture was heated to $100^{\circ} \mathrm{C}$ for 30 min under stirring, and, after cooling at room temperature, $20 \mathrm{~mL}$ of water were added and the FA methyl esters (FAMEs) were extracted in the hexane layer. Three more extractions with hexane were made to ensure complete removal of methyl esters.

For the FAMEs analyses an HP 5890 series II gas chromatograph (Hewlett Packard, Palo Alto, CA, USA) equipped with an autoinjector (model HP 6890) and FID detector was used. The separation was made in a Supelco Omega wax $250(30 \mathrm{~m} \times 0.25 \mathrm{~mm})$ fused silica capillary column $(0.25 \mu \mathrm{m})$. The oventemperature profile was: $205^{\circ} \mathrm{C}(10 \mathrm{~min}), 6^{\circ} \mathrm{C} / \mathrm{min}$ to $240^{\circ} \mathrm{C}(9 \mathrm{~min})$, for a total heating time of $25 \mathrm{~min}$. The identity of each individual FAME was determined by comparing retention times with a Sigma standard FAME mixtures. Replicates were made and mean values are shown in tables. The values of FAs are presented as percentages of the total FA mass. Heptadecanoic acid (17:0) methyl ester was used as the internal standard for quantitative analyses.

From the data on the FA composition, the index of atherogenicity (IA) and the index of thrombogenicity (IT) were calculated according to Ulbricht and Southgate (1991). The IA indicates the relationship between the sum of the main saturated and that corresponding to the main unsaturated FAs, the former being considered pro-atherogenic and the latter anti-atherogenic. The IT shows the tendency to form clots in the blood vessels. This is defined as the relationship between the pro-thrombogenic (saturated) and the anti-thrombogenic FA (MUFA, $n-6$ PUFA, $n$-3 PUFA). The value of flesh-lipid quality (FLQ) indicates the percentage relationship in which the main $n$-3 HUFA (EPA and DHA) appear in muscle with respect to total FAs. The higher value of this index, the greater the quality of the dietary FA source (Abrami et al., 1992).

\subsection{Statistics}

Data were analysed using a one-way ANOVA followed by a comparison of means (Tukey's LSD procedure). A significance level of 95\% was considered to indicate statistical differences $(\mathrm{p}<0.05)$. When results were expressed as a percentage (e.g. FA), the data were normalized using the arcsine transformation of their square root prior to statistical analysis, following Sokal and Rohlf (1981). All statistics were conducted using specific software (Statgraphics Plus 4.0, Statistical Graphics Corp., Rockville, Maryland, U.S.A.). 
TABLE 1. Proximate composition $\left(\mathrm{g} \cdot \mathrm{Kg}^{-1}\right.$ on dry weight) and fatty acid profile of the lipids in the diets (data are $\%$ of total fatty acids)

\begin{tabular}{|c|c|c|}
\hline Proximate composition & Microbaq & Alphamar \\
\hline Crude protein & 547.4 & 432.5 \\
\hline Crude lipid & 210.7 & 257.2 \\
\hline Ash & 101.1 & 59.3 \\
\hline Nitrogen-free extract* & 140.8 & 251.1 \\
\hline Energy $* *\left(\mathrm{MJ} \cdot \mathrm{Kg}^{-1}\right)$ & 22.00 & 22.32 \\
\hline Protein:energy ratio $\left(\mathrm{g} \cdot \mathrm{MJ}^{-1}\right)$ & 23.23 & 17.94 \\
\hline \multicolumn{3}{|l|}{ Fatty acid profile } \\
\hline \multicolumn{3}{|l|}{ SFAs $^{1}$} \\
\hline 14:0 (MA) & 4.87 & 2.47 \\
\hline 16:0 (PA) & 19.80 & 17.37 \\
\hline 18:0 (SA) & 4.47 & 4.70 \\
\hline \multicolumn{3}{|l|}{ MUFAs $^{2}$} \\
\hline $16: 1 n-7$ (POA) & 6.00 & 3.23 \\
\hline $18: 1 n-9(\mathrm{OA})$ & 14.90 & 22.20 \\
\hline $18: 1 n-7$ (VA) & 2.93 & 2.27 \\
\hline $20: 1 n-9$ (EEA) & 3.03 & 2.53 \\
\hline $22: 1 n-11(\mathrm{GA})$ & 3.10 & 2.43 \\
\hline \multicolumn{3}{|l|}{ PUFAs $^{3}$} \\
\hline $18: 2 n-6$ (LA) & 8.57 & 26.17 \\
\hline $18: 3 n-3$ (ALA) & 1.60 & 3.37 \\
\hline $18: 4 n-3(\mathrm{SA})$ & 1.53 & 0.70 \\
\hline $20: 4 n-6$ (AA) & 1.07 & 0.53 \\
\hline $20: 4 n-3$ (ETA) & 0.47 & 0.13 \\
\hline $20: 5 n-3$ (EPA) & 10.77 & 3.80 \\
\hline $22: 5 n-3$ (DPA) & 2.00 & 1.00 \\
\hline 22:6n-3 (DHA) & 13.03 & 6.77 \\
\hline ¿SFAs & 29.13 & 24.53 \\
\hline ¿MUFAs & 29.97 & 27.70 \\
\hline ¿PUFAs & 39.03 & 42.47 \\
\hline$\sum$ PUFAs $n-3^{4}$ & 29.40 & 15.77 \\
\hline ¿PUFAs $n-6^{5}$ & 9.63 & 26.70 \\
\hline$n-3: n-6$ & 3.05 & 0.59 \\
\hline
\end{tabular}

* calculated as $100-\left(\right.$ crude protein $\left(\mathrm{g} \cdot \mathrm{kg}^{-1}\right)+$ crude lipid $\left(\mathrm{g} \cdot \mathrm{kg}^{-1}\right)$ $\left.+\operatorname{ash}\left(\mathrm{g}^{\mathrm{kg}} \mathrm{kg}^{-1}\right)\right)$

** calculated on the basis of $24.3,39.7$ and $17.2 \mathrm{~kJ} \cdot \mathrm{g}^{-1}$ of protein, lipid and NFE, respectively

${ }^{1}$ Saturated fatty acids, ${ }^{2}$ Mono-unsaturated fatty acids,

${ }^{3}$ Polyunsaturated fatty acids, ${ }^{4} n-3$ Polyunsaturated fatty acids,

${ }^{5} n-6$ Polyunsaturated fatty acids.

\section{RESULTS AND DISCUSSION}

Regarding the lipid content of the main edible portion of fish (muscle), Table 2A shows that, over the period monitored, lipids steadily increased during the first year of caging (samples 1 to 8), after which the proportion of lipids in muscle stabilized or slightly fell.
The FA profiles of muscle lipids are shown in Tables 2A and 2B. In first samplings, the most abundant FAs were palmitic (PA, 16:0) among saturated (SFA), OA, 18:1n-9 among monounsaturated (MUFA), and docosahexaenoic (DHA, 22:6n-3) among polyunsaturated (PUFA). This situation persisted throughout the trial. For all groups, SFA and MUFA had a similar proportion of approximately $30 \%$, while PUFA were in the top of the range, with $39 \%$. In terms of the $n$ series, $n-3$ clearly predominated, accounting for almost four times the content of $n-6$ at the beginning of the experiment.

Throughout the trial, there were some statistically significant changes in this profile, although many of them can be considered physiologically minor or irrelevant. The most relevant changes included the significant increase in LA, 18:2n-6 among PUFAs and OA, as well as, to a lesser extent, MUFAs. Among the SFA the changes observed were minor, with no clear trend detected.

Since the OA increase was offset by the decline in other figures of this group (e.g., palmitoleic acid, PA, 16:1n-7) the overall MUFAs presented a slight oscillation over time, i.e. around a total of $30 \%$ with a peak in the sampling 4 that coincided with that of OA.

The total content of PUFAs varied markedly in the first samplings, reaching over $45 \%$ in the sampling 6 and showing a similar behaviour until the end of the experiment. Within this group, the increase in $n-6$ series, due largely to LA, was accompanied by a decrease in $n-3$ that affected mainly eicosapentaenoic acid (EPA, 20:5n-3). These simultaneous changes in $n-3$ and $n-6$ led to a fall in the $n-3: n-6$ ratio from initial values of 3.8 to values similar to and in some cases lower than 1.0. In relative terms, the greatest reduction in this ratio occurred between the samplings 3 and 4, after which a slow but incomplete recovery was detected.

The muscle-lipid content increased as the fish grew in the farm from $0.65 \%$ to $1.7-2 \%$ in wet matter. Total FAs varied over the experiment between $60-70 \%$ of lipids, in agreement with previous results on fish muscle and liver (Kandemir and Polat, 2007; Guil-Guerrero et al., 2011). Overall, lipid-content values proved clearly lower than those reported for other farmed fish (Grigorakis et al., 2011) and fully justify the common name (meagre, from maigre in French, meaning "lean") used for this species. The initial fattening of younger fish can be explained by the transition from a feeding based on highprotein/low-fat diets (hatchery diet and Microbaq) to a higher-fat diet. Both, Piccolo et al., (2008) and Chatzifotis et al., (2010) detected a higher proportion of lipids in meagre muscle when the fish was fed on high-fat diets (up to $21 \%$ ), but the highest value recorded $(20.7 \%$ lipids in diet, fish of $820 \mathrm{~g})$ was only $3.6 \%$. Poli et al. (2003) had previously reported meagre muscle fat-content values from $2.06 \%$ (fish 
Time course of muscle fatty acid composition of cultured meagre $\bullet 5$

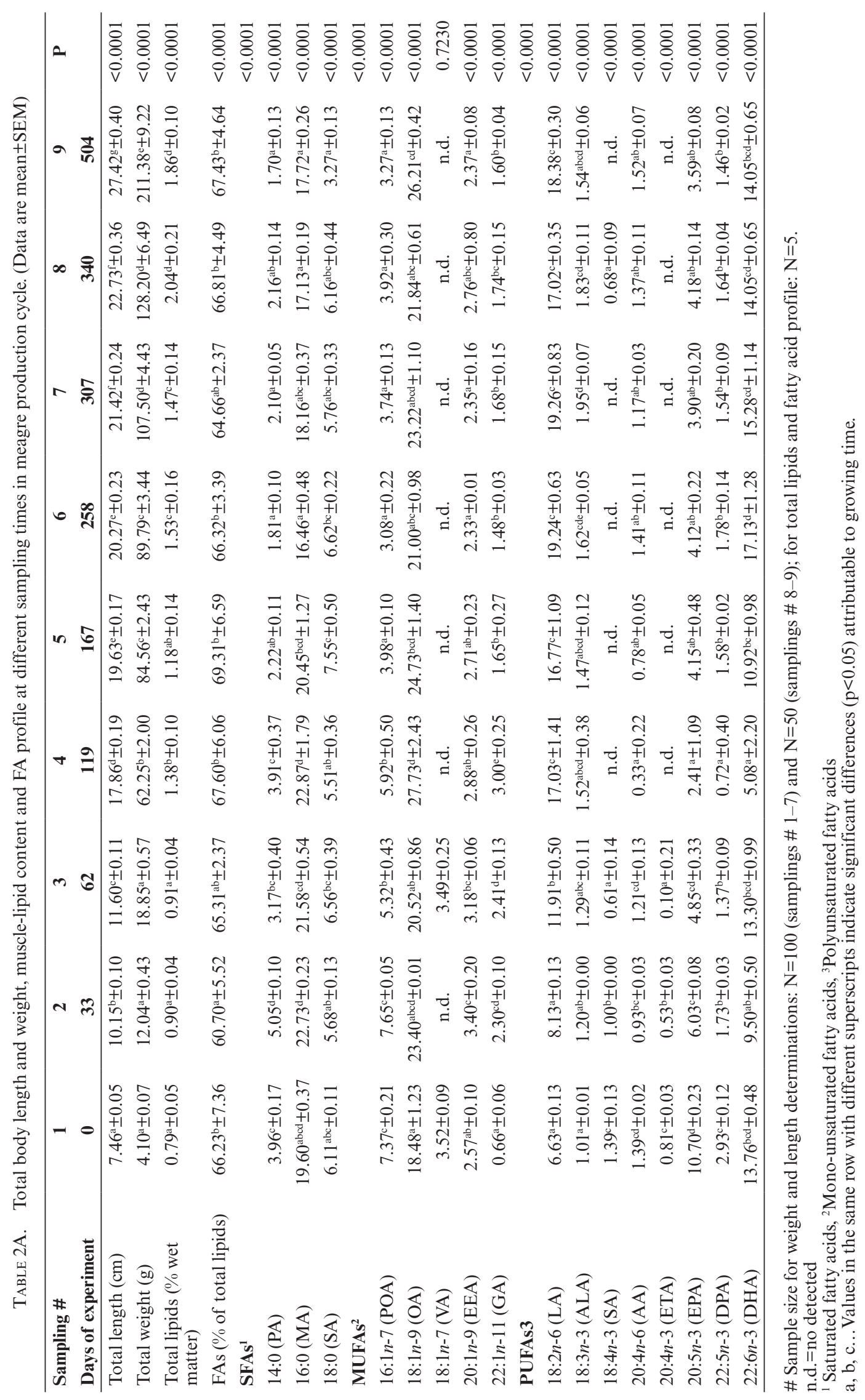

Grasas Aceites 65 (1), January-March 2014, e006. ISSN-L: 0017-3495 doi: http://dx.doi.org/10.3989/gya.049813 


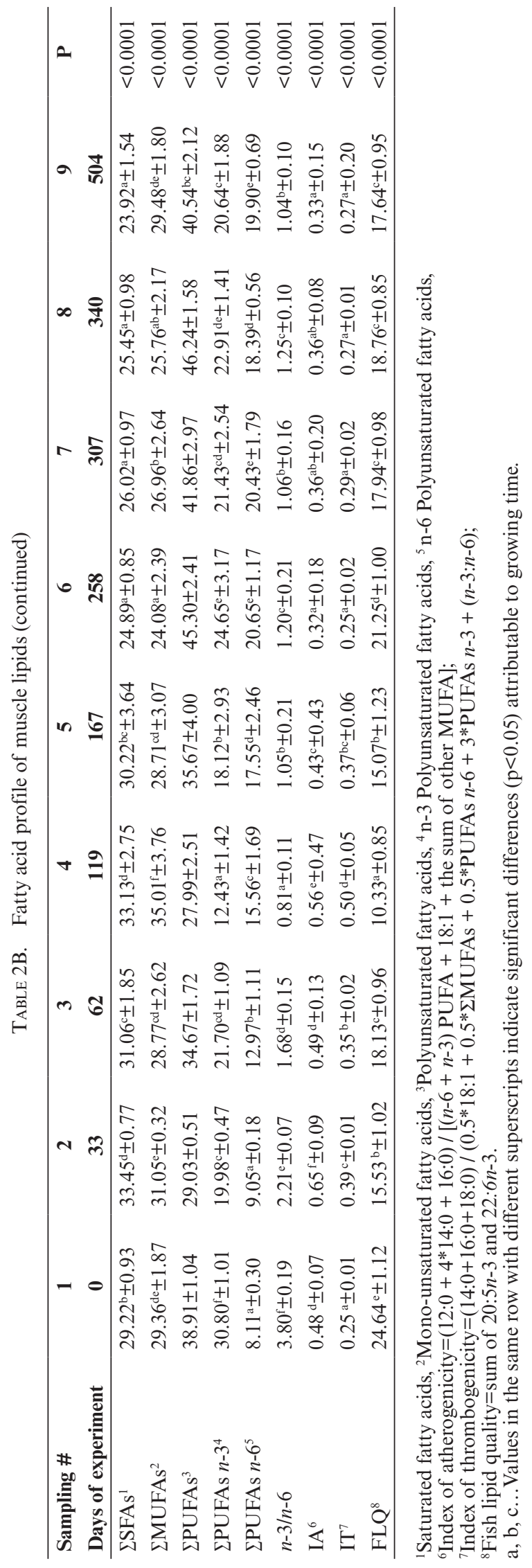

sampled in November) to $2.93 \%$ (fish sampled in July). Grigorakis et al. (2011) found 1.06\% content in 1280-g meagre sampled in December and fed with a commercial feed of $10 \%$ fat. In all cases, these low values confirm the high capacity of this fish to maintain reduced fat accumulation in muscle, despite being fed fat-rich diets, apparently reflecting a peculiar metabolism which bears further study.

Not only the total fat content of a fillet but also its FA profile concern human consumers. At the beginning of the experimental period (sampling 0) the juveniles exhibited muscle with a FA pattern having the following main characteristics: a) PA, $\mathrm{OA}$, and DHA as the figures most abundant in their respective groups of SFA, MUFA and PUFA; b) each of these groups represented approximately one third of total FA; and c) among the HUFA, a clear prevalence of the $n-3$ series with respect to $n-6$ series (ratio $n-3: n-6>>1$ ).

This situation could be considered representative of marine fish species in general (Lanari et al., 1999; Grigorakis et al., 2002; Yildiz et al., 2006), including meagre (Poli et al., 2003; Piccolo et al., 2008; Grigorakis et al., 2011). The high proportion of HUFAs $n-3$ is commonly attributed to the prevalence of these FA in the marine food web (Sargent and Henderson, 1995).

Frequently, factors such as water salinity, temperature, and physiological and dietary composition are considered the main determinants of possible changes in the fish FA profile. In this case the environmental salinity did not change appreciably throughout the experiment while temperature fluctuated only slightly (Figure 1). An increase in the proportion of HUFAs in fish lipids has been considered to be part of the process of adaptation to lower water temperatures, although data vary among species and type of lipids (neutral vs. polar lipids) (Greene and Selivonchick, 1987; Henderson and Tocher, 1987). In this case (Tables 2A, 2B), samples taken in the warmer season (samplings 2-3) were compared with those from colder one (samplings 5 and 9) showed no consistent differences in total HUFA levels or in EPA, DHA or AA. Data from other Mediterranean fish species (Yildiz et al., 2006; Senso et al., 2007) agree in that seasonal differences in the FA profile are minor or inexistent at least for the individual FA or FA groups cited above. Poli et al., (2003) detected some differences in the FA content of cultured meagre sampled in November and May-July (although the authors reported that water temperature varied from 17.2 to $28.6^{\circ} \mathrm{C}$ throughout the experiment, no data on water temperature in sampling days were provided) and thus $n$-3 PUFA, but also total SFA, were higher in fish sampled in November while total MUFA reduced in that season. The relatively high temperatures, even in winter, in the Mediterranean and adjacent Atlantic areas could underlie this lack of marked seasonal effects. 
On the other hand, it is difficult to define with precision the possible effects of water temperature upon the fish FA profile, when the corresponding studies are based on successive samplings from wild and/or farmed fish, since several biological variables such as fish age, reproductive status, changes in dietary composition (natural prey or artificial feed) could mask strictly abiotic environmental ones such as temperature.

In our assay, the most significant change over the whole period was perhaps the marked reduction in the $n-3: n-6$ ratio from an initial value close to 4.0 to a ratio of only about 1.0. This resulted from both a reduction in $n$-3 PUFA, mainly EPA, and a rise in LA content, the latter increasing by a factor of more than 3. Other marked changes affected the MUFA group, with a reduction in POA, 16:1n-7 and an increase in OA content. As a general trend, these changes were noticeable during the first part of the experiment, with a certain trend to stabilize thereafter.

Once again, the transition from the Microbaq diet, especially rich in $n$-3 HUFA (based on fish oil, as in commonly used hatchery diets), to the second diet used here (Alphamar), which incorporated higher levels of vegetable oils (as deduced from its high OA and LA levels, and the extremely low $n 3: n 6$ ratio, Table 1) was undoubtedly the main cause of the observed changes.

Figures 2 to 4, which display the time course of the fish-to-diet ratio (FtoD) for several representative individual or grouped FA, clearly show the convergence between FA composition of fish and diet for LA, 18:2n6 (the main figure in a lot of vegetal oils) and $n-3$ HUFA (the most abundant in fish oil). Both circumstances have reduced the FtoD $n-3: n-6$ ratio by a factor of close to four (Figure 4); a clear reduction in this ratio has also been detected in muscle of fish fed on diets with high proportions of plant oils in sea bass and sea bream (Grigorakis, 2007). Concerning individual $n-3$ HUFA, it is evident that fish have preserved the muscle levels of DHA at about two-fold higher that the dietary ones, while EPA FtoD showed a notable reduction to values close to one. This situation could be indicative of a specific greater need for DHA that could be accompanied by a conversion from EPA to DHA when the dietary supply of DHA was insufficient to meet the fish metabolic requirements. The practical disappearance of the initially reduced levels of other $\Delta 6$ desaturated $n-3$ precursors, such as stearidonic acid (SA, 18:4n-3) and eicosatrienoic acid (ETA, 20:3n-3), was also noticeable. The possible metabolic stress associated with this situation should be considered when formulating diets of low fish/high vegetal oil for fish culture, since not only muscle composition but fish growth and health could be negatively affected.

When the time course of the indices for fish-flesh lipid quality was considered (Table 2B), the situation proved unclear. In fact, FLQ became worse mainly due to EPA reduction, but when other HUFAs were included in the evaluation, such as in IA and IT, the negative effects of $n-3$ HUFA and $n-3: n-6$ reductions were partially counteracted by the beneficial effects of both lower SFA and higher MUFA and $n$-6. Previous studies with this species (Poli et al., 2003; Piccolo et al., 2008; Grigorakis et al., 2011) reported values of IA from 0.38 to 0.69 and IT values from 0.09 to 0.39 in the range of those found in this experiment and found in other cultured marine fish (Grigorakis, 2007).

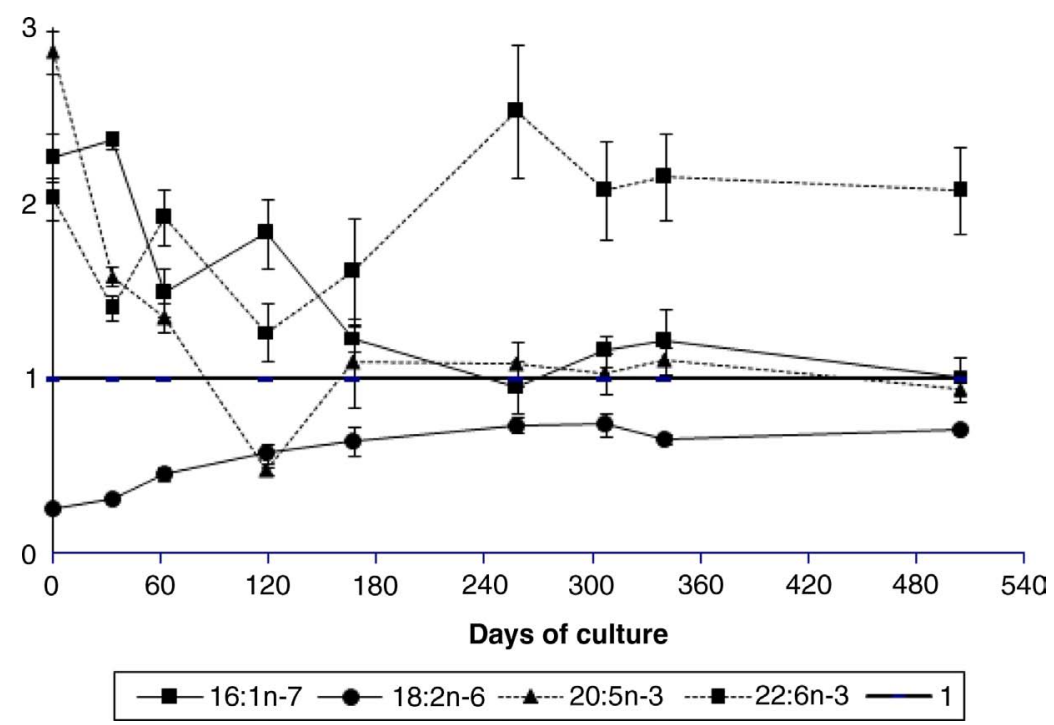

FIgURE 2. Time course of the ratio fish flesh to diet, (FtoD) of the relative content of several individual fatty acids of fish. 


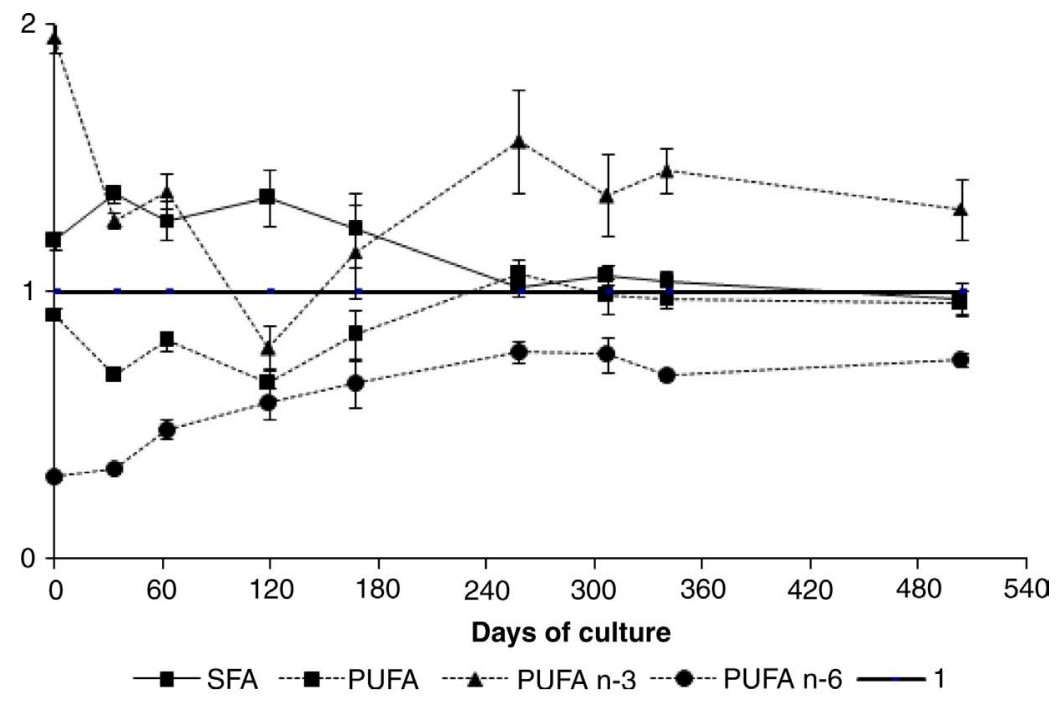

FIGURE 3. Time course of the ratio fish flesh to diet, (FtoD) of the relative content of several grouped fatty acids of fish. SFA: saturated fatty acids; MUFA: monounsaturated fatty acids; PUFA $n-3$ : polyunsaturated fatty acids of the $n$ - 3 series; PUFA $n-6$ : polyunsaturated fatty acids of the $n-6$ series.

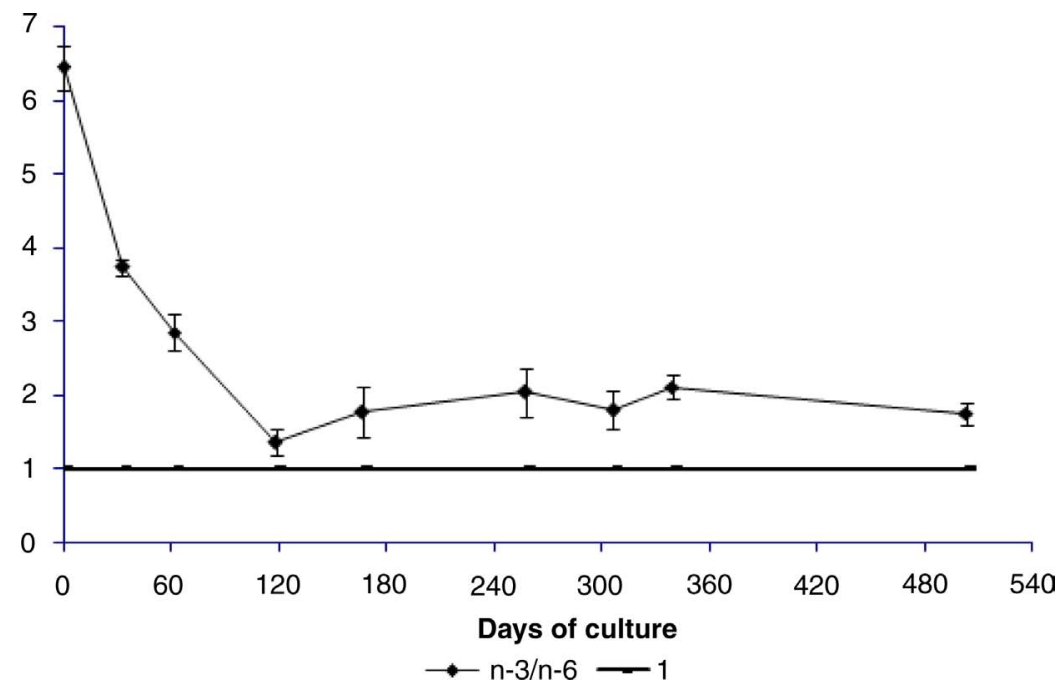

Figure 4. Time course of the diet fish flesh to diet ratio (FtoD) of the n-3:n-6 fatty acid ratio of fish.

\section{CONCLUSIONS}

The data compiled confirm the low fat content in meagre muscle in relation to other marine species, although values increased during culture. On the other hand, the muscle-fat FA content can be considered healthy for human consumption, values being similar to those found for cultured sea bass and sea bream, although when the culture plans include the use of plant-based lipid diets, the mixture of vegetal replacers of fish oil must be carefully designed. The use of high-HUFA $n 3$ ending-diets could also be taken in consideration.

\section{ACKNOWLEDGEMENTS}

Fish were reared in Ceutamar S.L. (Algeciras, Cádiz, Spain) facilities, and the further experimental work was carried out in the CEIA - -UAL.

\section{REFERENCES}

Abrami G, Natiello F, Bronzi P, McKenzie, D, Bolis L, Aggrade E. 1992. A comparison of highly unsaturated fatty acid levels in wild and farmed eels (Anguilla anguilla). Comp. Biochem. Physiol. 101, 79-81.

Ackman RG. 1995. Composition and nutritive value of fish and shellfish lipids. In Ruiter, A. (Ed.) Fish and Fishery Products. Cab Int pp. 117-156. 
AOAC, 2000. Official methods of analysis. AOAC International. William Horwitz Ed. Washington DC, USA.

Chatzifotis S, Panagiotidou M, Papaioannou N, Pavlidis M, Nengas I, Mylonas CC. 2010. Effect of dietary lipid levels on growth, feed utilization, body composition and serum metabolites of meagre (Argyrosomus regius) juveniles. Aquaculture 307, 65-70.

Folch J, Lees M, Sloane-Stanley GH. 1957. A simple method for the isolation and purification of total lipids from animal tissues. J. Biol. Chem. 226, 497-509.

Greene DHS, Selivonchick DP. 1987. Lipid metabolism in fish. Progress in Lipid Research 26, 53-85.

Grigorakis K, Alexis MN, Taylor KDA, Hole M. 2002. Comparison of wild and cultured gilthead sea bream; composition, appearance and seasonal alterations. Int. J. Food Sci. Technol. 37, 477-484.

Grigorakis K. 2007. Compositional and organoleptic quality of farmed and wild gilthead sea bream (Sparus aurata) and sea bass (Dicentrarchus labrax) and factors affecting it: a review. Aquaculture 272, 55-75.

Grigorakis K, Fountoulaki E, Vasilaki E, Mittakos I Nathanailides Cf. 2011. Lipid quality and filleting yield of reared meagre (Argyrosomus regius). Int. J. Food Sci. Technol. 46, 711-716.

Guil-Guerrero JL, Venegas-Venegas E, Rincón-Cervera MA, Suárez MD. 2011. Fatty acid profiles of livers from selected marine fish species. J. Food Comp. Anal. 24, 217-222.

Henderson RJ, Tocher DR. 1987. The lipid composition and biochemistry of freshwater fish. Prog. Lipid Res. 26, 281-347.

Hassan M, Chatha SAS, Tahira I, Hussain B. 2010. Total lipids and fatty acid profile in the liver of wild and farmed catla catla fish. Grasas Aceites 61, 52-57.

Hernández MD, Lopez MB, Alvarez A, Ferrandini E, Garcia BG, Garrido MD. 2009. Sensory, physical, chemical and microbiological changes in aquacultured meagre (Argyrosomus regius) fillets during ice storage. Food Chem. 114, 237-245.

Hussain B, Mahboob S, Hassan M, Nadeem S, Sultana, T. 2011. Effect of maturation degree on fatty acid profile of different tissues in wild and farmed rohu (Labeo rohita). Grasas Aceites 62, 206-212.

Kandemir S, Polat N. 2007. Seasonal variation of total lipid and total fatty acid in muscle and liver of Rainbow trout (Oncorhynchus mykiss W., 1792) reared in Derbent Dam Lake. Turk. J. Fish. Aquatic Sci. 7, 27-31.

Lanari D, Poli BM, Ballestrazzi R, Lupi P, D'Agaro E, Mecatti M. 1999. The effects of dietary fat and NFE levels on growing European sea bass (Dicentrarchus labrax L.). Growth rate, body and fillet composition, carcass traits and nutrient retention efficiency. Aquaculture 179, 351-364.

Leger C, Bergot P, Lekuet P, Flanzy J, Meurot J. 1977. Specifik distribution of fatty acids in the triglycerides of rainbow trout adipose tissue. Influence of Temperature. Lipids 12, $538-543$.
Lie O. 2001. Flesh quality - the role of nutrition. Aquacult. Res. 32, 341-348

Nasopoulou C, Nomikos T, Demopoulos CA, Zabetakis I. 2007. Comparison of antiatherogenic properties of lipids obtained from wild and cultured sea bass (Dicentrarchus labrax) and gilthead sea bream (Sparus aurata). Food Chem. 100, 560-567.

Piccolo G, Bovera F, De Riu N, Marono S, Salati F, Cappuccinelli R, Moniello G. 2008. Effect of two different protein/ fat ratios of the diet on meagre (Argyrosomus regius) traits. Ital. J. Anim. Sci. 7, 363-371.

Pirini M, Testi S, Ventrella V, Pagliarani A, Badiani A. 2010. Blue-back fish: Fatty acid profile in selected seasons and retention upon baking. Food Chem. 123, 306-314.

Poli BM, Parisi G, Zamapacavall G, Lurzan F, Mecatti M, Lupi P, Bonelli A. 2003. Preliminary results on quality and quality changes in reared meagre (Argyrosomus regius): body and fillet traits and freshness changes in refrigerated commercial-size fish. Aquacult. Internat. 11, 301-311.

Rodríguez-Ruiz J, El Belarbi H, García Sánchez JL, López Alonso D. 1998. Rapid simultaneous lipid extraction and transesterification for fatty acid analyses. Biotechnol. Techn. 12, 689-691

Sargent JR, Henderson RJ. 1995. Marine n-3. polyunsaturated fatty acids. in Hamilton, R.J. (Ed.). Developments in Oils and Fats. Blackie Academic and Professional, London. pp. $32-65$.

Senso L, Suárez MD, Ruiz-Cara T, García-Gallego M. 2007. On the possible effects of harvesting season and chilled storage on the fatty acid profile of the fillet of farmed gilthead sea bream (Sparus aurata). Food Chem. 101, 298-307.

Shirai N, Suzuki H, Tokairin S, Ehara H, Wada S. 2002. Dietary and seasonal effects on the dorsal meat lipid composition of Japanese (Silurus asotus) and Thai catfish (Clarias macrocephalus and hybrid Clarias macrocephalus and Clarias galipinus). Comp. Biochem. Physiol. 132, 609-619.

Sokal R, Rohlf JF. 1981. Biometry, the principles and practice of statistics. in Biological research (2nd ed.). Freeman, San Francisco, $861 \mathrm{pp}$.

Ulbricht TL, Southgate DAT. 1991. Coronary heart disease: seven dietary factors. The Lancet 338, 985-992.

WHO/FAO. 1977. Dietary fats and oils in human nutrition. Report of an expert consultation. FAO, Rome.

Yildiz M, Sener E, Tumur, M. 2006. The effects of seasons and different feeds on fatty acid composition in fillets of cultured gilthead sea bream (Sparus aurata L.) and European Sea Bass (Dicentrarchus labrax L.) in Turkey. Turk. J. Vet. Anim. Sci. 30, 133-141.

Yildiz M, Şener E, Timur M. 2008. Effects of differences in diet and seasonal changes on the fatty acid composition in fillets from farmed and wild sea bream (Sparus aurata L.) and sea bass (Dicentrarchus labrax L.). Int. J. Food Sc. Technol. 43, 853-858. 